Research Article/Araştırma Makalesi

Investigation of the Relationship between Spatial Habits of Mind and Visual Literacy Competences through Structural Equation Model

\author{
Neşe DOKUMACI SÜTÇÜ* 1 (D) \\ ${ }^{1}$ Dicle University, Faculty of Education, Diyarbakur, Turkey, ndokumaci@dicle.edu.tr \\ * Corresponding Author: ndokumaci@dicle.edu.tr
}

\begin{tabular}{|c|c|}
\hline Article Info & Abstract \\
\hline $\begin{array}{ll}\text { Received: } & 15 \text { December } 2020 \\
\text { Accepted: } & 9 \text { March } 2021\end{array}$ & $\begin{array}{l}\text { This study aims to examine the relationship between the spatial habits } \\
\text { of mind and visual literacy competences of teacher candidates with } \\
\text { structural equation model. The research, designed in correlational } \\
\text { survey pattern, has been carried out with } 235 \text { teacher candidates } \\
\text { selected with convenience sampling method. The data were collected } \\
\text { by the "Scale of Spatial Habits of Mind" and the "Scale of Visual } \\
\text { Literacy competences" Descriptive statistics. Pearson Product-Moment }\end{array}$ \\
\hline $\begin{array}{l}\text { Keywords: Spatial habits of mind, } \\
\text { visual literacy competences, } \\
\text { structural equation model }\end{array}$ & $\begin{array}{l}\text { Correlation Coefficient and structural equation model were used in the } \\
\text { research. Before proceeding with the structural equation model, } \\
\text { measuring models were tested one by one using confirmatory factor }\end{array}$ \\
\hline doi $10.18009 /$ jcer. 840318 & $\begin{array}{l}\text { analysis. According to the research results, it has been found that there } \\
\text { is a positive and significant relation between the spatial habits of mind }\end{array}$ \\
\hline Publication Language: Turkish & $\begin{array}{l}\text { and visual literacy competences, and that the spatial habits of mind are } \\
\text { a significant predictor of visual literacy competences. }\end{array}$ \\
\hline
\end{tabular}

open access ( CrossMark (C)

To cite this article: Dokumacı-Sütçü, N. (2021). Zihnin uzamsal alışkanlıkları ile görsel okuryazarlık yeterlilikleri arasındaki ilişkinin yapısal eşitlik modeli ile incelenmesi. Journal of Computer and Education Research, 9 (17), 125-144. DOI: 10.18009/jcer.840318

\title{
Zihnin Uzamsal Alışkanlıkları ile Görsel Okuryazarlık Yeterlilikleri Arasındaki İlişkinin Yapısal Eşitlik Modeli ile İncelenmesi
}

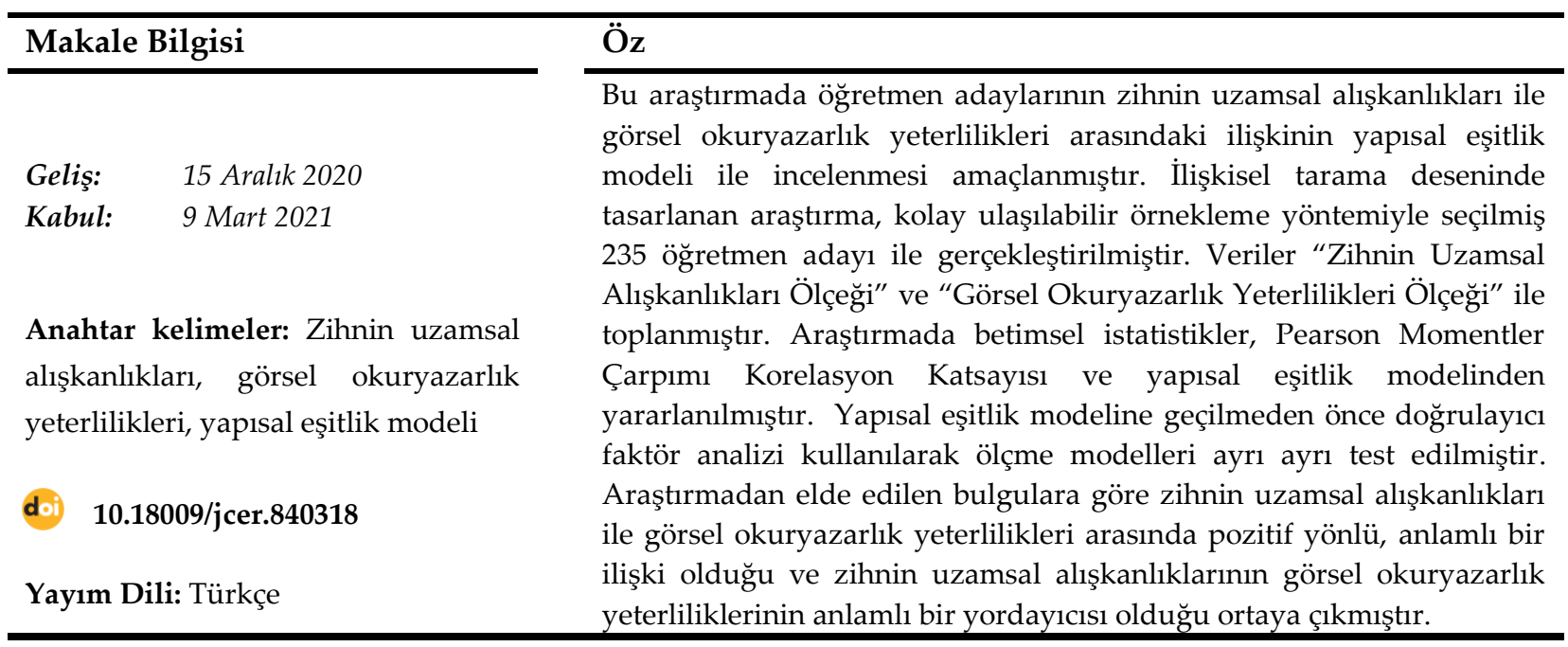




\title{
Summary
}

\section{Investigation of the Relationship between Spatial Habits of Mind and Visual Literacy Competences through Structural Equation Model}

\author{
Neşe DOKUMACI SÜTÇÜ* 1 \\ ${ }^{1}$ Dicle University, Faculty of Education, Diyarbakır, Turkey, ndokumaci@dicle.edu.tr \\ * Corresponding Author: ndokumaci@dicle.edu.tr
}

\section{Introduction}

Contemporary culture is changing every day, depending on the visuals and the communication with them. In this visual age we are in, we are surrounded by visuals more than ever. Thus, it is now much more crucial than ever to have and be able to use skills such as visual perception, visual reading, and visualization (Eraslan-Taşpınar, 2016). Considering that the great scientific discoveries of the nineteenth and twentieth centuries are mostly due to the visualization and interpretation skills of scientists (Milner-Bolotin \& Nashon, 2012), it is needed to examine the spatial habits of mind and visual literacy competences of teacher candidates. There are researches about visual literacy of teacher candidates available (Eraslan-Taşpınar, 2016; Şahin \& Kıran, 2009; Şahin, Kurudayığlu \& Çelik, 2013) in the related field literature. Despite this, the number of studies conducted on the spatial habits of mind (Çeker, 2018) seems to be limited. In addition, no research has been found in the field literature examining the relationship between the spatial habits of mind and visual literacy competences of the teacher candidates. For this reason, the present study aims to examine the relationship between the spatial habits of mind and visual literacy competences of teacher candidates with structural equation model. In line with this, responds were sought for the questions below:

- Is there a significant relation between the spatial habits of mind and competence in visual literacy?

- Are the spatial habits of mind a meaningful predictor of visual literacy competences? 


\section{Method}

The correlational survey model has been used in this study, which aims to examine the relation between the spatial habits of mind and visual literacy competences. Participants of the research consist of 235 teacher candidates selected by the convenience sampling method (because of time, cost and ease of sampling), who study during the fall semester of the 2019-2020 academic year in the Education Faculty of a public university located in the Southeastern Anatolia Region in Turkey. The data were collected by the "Scale of Spatial Habits of Mind" and the "Scale of Visual Literacy Competences". Descriptive Statistics, Pearson Product-Moment Correlation Coefficient and Structural Equation Model were used in the research. Before proceeding with the structural equation model, measuring models were tested one by one using confirmatory factor analysis.

\section{Results}

It has been found that there is a positive significant relation between the spatial habits of mind and visual literacy competences $[\beta=.80, t=7.74$ and $p<.001]$ and that it explains $63 \%$ of the common variance between two potential variables $\left[R^{2}=.63\right]$. In the measuring model of the spatial habits of mind, the potential variable of the spatial habits of mind explains $41 \%$ of the variance in "pattern recognition", $44 \%$ of the variance in "spatial description", $49 \%$ of the variance in "visualization", $39 \%$ of the variance in the "spatial concept use", and 35\% of the variance in the use of "spatial tool use". In the measuring model of visual literacy competences, however, the potential variable of the visual literacy competences explains 35\% of the variance in "giving importance to visuality by using office software", 53\% of the variance in "illustrating published visual materials", $46 \%$ of the variance in "visual interpretation", $28 \%$ of the variance in "discriminating daily encountered visual messages", $29 \%$ of the variance in "producing visuality by utilizing from tools", and $53 \%$ of the variance in "perceiving messages in the visuals".

\section{Discussion and Conclusion}

According to research results, it has been found that there is a positive significant relation between the spatial habits of mind and visual literacy competences and thus the first hypothesis has been verified. This finding means that improving the spatial habits of their minds will positively affect the visual literacy competences of teacher candidates. According to another finding of the result, the spatial habits of mind is a meaningful predictor of the 
visual literacy competences of the teacher candidates, which verifies the second hypothesis as well. Accordingly, it has been found that the spatial habits of mind explain $63 \%$ of the variance in visual literacy competences. This finding means that the spatial habits of mind is a significant effect on the visual literacy competences of teacher candidates. Similarly, Kim and Bednards (2013) stated that bearing spatial habits of mind is crucial for visual-spatial literacy competences. The spatial habits of mind explain the variance in the dimension of "visualization" at most. The reason of this can be explained by the fact that the dimension of visualization has a closer relation with visual literacy competences and its sub-dimensions. Because visualization is the effort to comprehend with the help of graphic representations (Blaser, Sester \& Egenhofer, 2000). On the other hand, visual literacy competences explain the variance in the dimension of "ability to identify printed visual materials" at most.

This research has been conducted with the science and math teacher candidates studying in a public university located in the Southeastern Anatolia region. For this reason, similar researches can be conducted with teacher candidates in different branches studying in different universities. The research examined the predicting effect of the spatial habits of mind on the visual literacy competences of teacher candidates. In future research projects, different variables that may affect the visual literacy competence of teacher candidates may also be included. 


\section{Giriş}

Bir sonuca ulaşmak için var olan kavramların ve ilkelerin ilişkilendirildiği düşünme süreci, bir takım zihinsel alışkanlıklarla işler ve gelişir (Köse \& Tanışlı, 2014). Zihin alışkanlıkları, belirli bir perspektife yönelik içselleştirilmiş düşünme süreçleri (Kim, 2011) olarak tanımlandığı gibi, bireylerin bir problemin üstesinden gelmeye çalışırken tercih ettikleri stratejiler ve eğilimler olarak da tanımlanmaktadır (Ünveren-Bilgiç \& Argün, 2018). Birçok beceri, tutum, ipucu, geçmiş deneyim ve eğilimlerin bir bileşimi olan zihin alışkanlıklarını (Costa, 2008) kullanmak, etkili entelektüel davranış kalıplarını seçme eğilimi ve yeteneği anlamına gelir. Zihin alışkanlıklarının psikolojik özellikleri arasında kişisel sebat, etkili bir strateji seçme eğilimi ve bu stratejiyi problemli durumu çözmek için uygulama becerisi yer alır (Leikin, 2007). Marzano (1992) zihin alışkanlıklarının öğrenmenin beş boyutundan biri olduğunu ortaya koymuş ve bu boyutları öğrenmeye ilişkin olumlu tutum ve algılar, bilgi edinme ve bütünleştirme, bilgiyi genişletme ve iyileştirme, bilgiyi anlamlı bir şekilde kullanma ve zihin alışkanlıkları şeklinde ifade etmiştir.

Zihin alışkanlıkları mevcut sorunlarla yüzleşerek kullanıldığında zekasını geliştirebilen birinin sahip olduğu bir beceri (Marita, 2014) olduğundan dolayı herkes için özellikle öğrenciler için çok önemlidir çünkü öğrenciler yüksek zihin alışkanlıklarına sahip olduklarında çeşitli sorunları kendi yöntemleriyle kolayca çözme fırsatına sahip olacaklardır (Astatin, Mayasari, Huriawati \& Oi, 2020). Zihin alışkanlıkları konusunda çalışma yapan Cuoco, Goldenberg ve Mark (1996) yapmış oldukları araştırmada öğrencilerin geliştirmeleri istenilen genel yaklaşımları; bazı yararlı genel zihin alışkanlıkları ve yıllar içinde kendini değerli gösteren bazı matematiksel yaklaşımlar olarak ifade etmişlerdir. Bununla birlikte; öğrencilerin sahip olmaları gereken içeriğe özgü alışkanlıkları da, matematiksel yaklaşımları destekleyen bazı geometrik zihin alışkanlıkları ve geometrik yaklaşımları tamamlayan bazı cebirsel zihin alışkanlıkları olarak belirtmişlerdir.

Zihnin genel alışkanlıkları; örüntüyü keşfetme, deney yapma, tanımlama, fikirleri parçalara ayırma ve yeniden bir araya getirme, mucit olma, görselleştirme, hipotez kurma ve tahmin etmedir (Cuoco vd., 1996). Zihnin matematiksel alışkanlıkları, matematik problemlerine yaklaşmanın ve matematikçiler tarafından kullanılan yöntemlere benzeyen matematiksel kavramlar hakkında düşünmenin özel yollarının ağı olarak tanımlanmaktadır (Goldenberg, Mark \& Cuoco, 2010). Buna göre matematiğe dair zihin alışkanlıkları; genel konuşma ve detaylı düşünme, detaylı konuşma ve genel düşüme, fonksiyonları kullanma, 
aynı şeyi birkaç farklı açıdan düşünme, tümdengelim ve deneyi karıştırma, sonuçları yeni durumlara uyarlama, entelektüel tekrarları kullanmadır (Cuoco vd., 1996).

Zihnin matematiksel alışkanlıklarına sahip olmak, matematiğin geometri ve cebir gibi alanlarında daha ön plana çıkarak zihnin geometrik ya da cebirsel alışkanlıkları olarak ifade edilmektedir. Zihnin geometrik alışkanlıkları, geometrik kavramların uygulanmasını ve öğrenmesini destekleyen üretici düşünme yollarıdır (Köse \& Tanışlı, 2014). Buna göre geometriye dair zihin alışkanlıkları orantılı muhakeme yapma, aynı anda birçok tekniği kullanma, her şey için tek bir dil kullanma, sistemleri sevme, değişen ve değişmeyen şeyleri merak etme ve şekilleri sevmedir. Cebire dair zihin alışkanlıkları ise hesap yapmaktan hoşlanma, soyutlama yapma, algoritmadan hoşlanma, bütünü parçalarına ayırma, genişletme yapma ve değişkenlere temsilci atamadır (Cuoco vd., 1996; Kaya, 2011).

Kim (2011), Cuoco ve diğerlerinin (1996) tanımladıkları zihnin genel alışkanlıklarından faydalanmış; zihnin uzamsal alışkanlıklarını ve alt boyutlarını tanımlamaya çalışmıştır. Buna göre; uzamsal zihin alışkanlıkları, uzamsal kavramların ve muhakemenin anlaşılması ve uzamsal formlar aracılığıyla fikirleri temsil etme ve ifade etme gibi uzamsal düşünme biçimlerinin kullanıldığı içselleştirilmiş düşünme süreçleri olarak tanımlanabilir. Kim'e (2011) göre uzamsal zihin alışkanlıklarının alt boyutları örüntü tanıma, uzamsal tanımlama, görselleştirme, uzamsal kavram kullanımı ve uzamsal araç kullanımıdır. "Örüntü tanıma” zihinsel alışkanlığını kullanan bireyler, çok çeşitli durumlarda uzamsal örüntüleri belirlemeye çalışırlar. "Uzamsal tanımlama" zihinsel alışkanlığını kullanan bireyler uzamsal kelimeleri ustaca kullanırlar. "Görselleştirme" zihinsel alışkanlığı kullanan bireyler, grafiksel gösterimler yardımıyla olayları anlamaya çalışırlar. “Uzamsal kavram” zihinsel alışkanlığı kullanan bireyler çeşitli görevleri anlamak ve gerçekleştirmek için uzamsal kavramları kullanırlar. "Uzamsal araç” zihinsel alışkanlığı kullanan bireyler ise haritalar, Google Earth veya GIS gibi uzamsal araçlarla uzamsal düşünmeyi desteklerler. Kim (2011) uzamsal zihin alışkanlıklarının alt boyutlarının özellikleri dikkate alındığında insanların zihnin uzamsal alışkanlıklarına sahip olmalarının görsel-uzamsal okuryazarlık için önemli olduğunu belirtmiştir.

Görsel okuryazarlık bir imgenin, verilmek istenen mesaja göre oluşturulması, düzenlenmesi, sunulan mesajın okunması ve yorumlanmasıdır (Yüksel-Gemalmayan, 2014). Görsel öğeleri okuma, anlama, bu öğelerle düşünebilme ve öğrenebilme yeterliği (Zeren \& Arslan, 2009) olan görsel okuryazarlık, görsel mesajları oluşturma ve anlamlandırma gücü 
olarak da tanımlanabilir (Kiper, Kırksekiz \& Çam, 2014). Ortak bir görsel okuryazarlık tanımına ilişkin araştırmacılar arasında önemli anlaşmazlıklar olmasına rağmen araştırmacıların çoğu görsel okuryazarlığı resimlerin görselleştirilmesi ve anlaşılması olarak ele almışlardır. Farklı araştırmacılar tarafından görsel okuryazarlık bir beceri, bir yetkinlik ya da bir yetenek olarak adlandırılmıştır. Görsel okuryazarlık becerileri, ışığı karanlıktan ayırt etme becerisinden, bir duyguyu ifade etmek için vücut dilini kullanma becerisine kadar uzanır. Görsel okuryazarlık yetenekleri görsel ifadeleri okuma, kod çözme, yorumlama, görsel ifadeleri yazma, kodlama, oluşturma ve görsel olarak düşünmektir. Görsel okuryazarlık yeterlikleri ise kasıtlı iletişim için yapılmış görselleri okumak; kasıtlı iletişim için görseller planlamak; kasıtlı iletişim için görseller oluşturmak; kasıtlı iletişim için görselleri ve fiilleri birleştirmektir (Avgerinon \& Pettersson, 2011). Görsel okuryazarlık tanımları, görsel okuryazarlığın bireyin öğrenme ve öğretme sürecine katkı sağlayacak kapsamlı bir yeti olduğunu göstermektedir (Alpan, 2008). Günümüz bilgi toplumunda görsel öğelerin, materyallerin, mesajların kullanılması gittikçe daha önemli olmakta ve bireyler açısından görsel okuryazar olmayı gerekli hale getirmektedir (Kiper vd., 2014). Çünkü öğrencilerin görsel-uzamsal okuryazarlık becerilerine sahip olmaları, fen, matematik ve mühendislik alanlarındaki başarıları için kritik bir öneme sahiptir (Milner-Bolotin \& Nashon, 2012).

Çağdaş kültür, görsellere ve görsellerle kurulan iletişime bağlı bir biçimde her geçen gün değişmekte dolayısıyla içinde bulunduğumuz görsel çağda etrafımız her zamankinden daha çok görsellerle çevrilmektedir. Dolayısıyla görsel okuma, görsel algılama, görselleştirme gibi becerilere sahip olmak ve bu becerileri kullanabilmek her zamankinden çok daha önemli hale gelmektedir (Eraslan-Taşpınar, 2016). On dokuzuncu ve yirminci yüzyılların büyük bilimsel keşiflerinin büyük ölçüde bilim adamlarının görselleştirme ve yorumlama becerilerine dayandığı düşünüldüğünde (Milner-Bolotin \& Nashon, 2012) öğretmen adaylarının zihnin uzamsal alışkanlıkları ile görsel okuryazarlık yeterliliklerinin incelenmesine ihtiyaç duyulmaktadır. İlgili alan yazında farklı okuryazarlık çeşitleri (matematik, fen ve teknoloji, bilimsel, medya, dijital, çevre, bilgi, fen bilimleri) ile ilgili çok sayıda araştırma (Akkoyunlu \& Yılmaz, 2005; Benzer, 2020; Kaya, 2017; Kaya \& Elster, 2019; Kul, 2020; Özgen \& Kutluca, 2013; Sadıç \& Çam, 2015) olduğu gibi öğretmen adaylarının görsel okuryazarlıkları ile ilgili yapılan araştırmalarda (Eraslan-Taşpınar, 2016; Şahin \& Kıran, 2009; Şahin, Kurudayığlu \& Çelik, 2013) mevcuttur. Buna rağmen zihnin uzamsal 
alışkanlıkları ile ilgili yapılan çalışmaların (Çeker, 2018) sınırlı sayıda olduğu görülmektedir. Bununla birlikte alanyazında öğretmen adaylarının zihnin uzamsal alışkanlıkları ile görsel okuryazarlık yeterliliklerinin arasındaki ilişkinin incelendiği herhangi bir araştırmaya rastlanmamıştır. Bu nedenle öğretmen adaylarının zihnin uzamsal alışkanlıkları ile görsel okuryazarlık yeterlilikleri arasında nasıl bir ilişki olduğu merak konusu olmuştur.

\section{Araştırmanın Amacı}

$\mathrm{Bu}$ araştırmada öğretmen adaylarının zihnin uzamsal alışkanlıkları ile görsel okuryazarlık yeterlilikleri arasındaki ilişkinin yapısal eşitlik modeli ile incelenmesi amaçlanmıştır. Bu doğrultuda aşağıda verilen sorulara yanıt aranmıştır:

- Zihnin uzamsal alışkanlıkları ile görsel okuryazarlık yeterlilikleri arasında anlamlı bir ilişki var mıdır?

- Zihnin uzamsal alışkanlıkları görsel okuryazarlık yeterliliklerinin anlamlı bir yordayıcısı midır?

\section{Yöntem}

\section{Araştırma Deseni}

Zihnin uzamsal alışkanlıkları ile görsel okuryazarlık yeterlilikleri arasındaki ilişkinin incelenmesini amaçlayan bu araştırmada ilişkisel tarama modeli kullanılmıştır. İlişkisel tarama modeli, iki veya daha fazla değişken arasındaki ilişkileri belirlemek ve bunların neden ve sonuç üzerindeki etkilerini keşfetmek için kullanılır. Bu tür araştırmalar, daha akıllı tahminler yapmamıza yardımcı olabilir (Fraenkel, Wallen \& Hyun, 2012).

\section{Araştırmanın Katılımcıları}

Araştırmanın katılımcıları, 2019-2020 eğitim-öğretim yılı güz döneminde Güneydoğu Anadolu Bölgesi'nde bulunan bir devlet üniversitesinin eğitim fakültesinde öğrenim gören kolay ulaşılabilir örnekleme (zaman, maliyet ve örnekleme ulaşma kolaylı̆̆ı nedeniyle) yöntemiyle seçilmiş 235 öğretmen adayından oluşmaktadır. Ölçek ilk aşamada 251 öğretmen adayına uygulanmış ancak yanlış ya da eksik doldurulan 11 ve varsayım analizleri neticesinde uç değer oldukları belirlenen 5 ölçek araştırma kapsamından çıkarılmıştır. Ortaöğretim matematik öğretmenliğinde öğrenim gören öğrenci sayısı az olduğu için ilköğretim matematik ve ortaöğretim matematik öğretmenliği öğrencileri birleştirilerek matematik öğretmenliği adı altında araştırmaya dâhil edilmiştir. Buna göre öğretmen 
adaylarının 163'ü (\%69.4) kadın, 72'si (\%30.6) erkek; 126'sı (\%53.6) matematik, 109’u (\%46.4) ise fen bilgisi öğretmen adayıdır. Bununla birlikte öğretmen adaylarının 73’ü (\%31.1) 1.sınıf, 66'sı (\%28.1) ikinci sinıf, 49'u (\%20.9) 3. sinıf ve 47'si (\%20.0) ise 4. sinıftır.

\section{Veri Toplama Araçları}

$\mathrm{Bu}$ araştırmada veriler "Zihnin Uzamsal Alışkanlıkları Ölçeği" ve "Görsel Okuryazarlık Yeterlilikleri Ölçeği" ile toplanmıştır.

Zihnin Uzamsal Alışkanlıkları (ZUA) Ölçeği; Kim (2011) tarafından geliştirilmiş, Çeker (2018) tarafından Türkçe'ye uyarlanmıştır. 27 maddeden oluşan ölçek 5'li Likert tipindedir. Ölçekteki maddeler; "Kesinlikle katılmıyorum=1", "Katılmıyorum=2", "Kararsızım=3", "Katılıyorum=4" ve "Kesinlikle katılıyorum=5" şeklinde derecelendirilmiştir. Ölçek beş alt boyuttan oluşmaktadır. Ölçeğin alt boyutları 6 maddeden oluşan “Örüntüyü Fark Etme (ÖFE)”, 5 maddeden oluşan “Uzamsal Tasvir (UT)”, 7 maddeden oluşan “Görselleştirme (G)”, 4 maddeden oluşan “Uzamsal Kavram Kullanımı (UKK)”, 5 maddeden oluşan “Uzamsal Araç Kullanımı (UAK)” olarak belirlenmiştir. Ölçeğin iç tutarlılık katsayısı .89 olarak rapor edilmiştir. Bu araştırma kapsamında ölçeğin iç tutarlılık katsayısı .85 olarak hesaplanmıştır. Tablo 1'de ZUA ölçeğinin her boyutuna ilişkin örnek madde verilmiştir.

Tablo 1. ZUA ölçeğinin her boyutuna ilişkin madde

\begin{tabular}{cl}
\hline Boyutlar & \multicolumn{1}{c}{ Örnek Madde } \\
\hline ÖFE & $\begin{array}{l}\text { Bir güzergahı bulmak için harita kullandığımda, yol ağındaki tüm örüntüleri fark etme } \\
\text { eğilimim vardır. }\end{array}$ \\
\hline UT & Konum, yön, yayılma ve ağ gibi uzamsal sözcükleri nadiren kullanırım. \\
\hline G & $\begin{array}{l}\text { Grafiklerin, çizelgelerin ya da haritaların yeni kavramları öğrenmeme yardımcı } \\
\text { olduğunu anladım. }\end{array}$ \\
\hline UKK & Konum ve ölçek gibi uzamsal kavramlar, problem çözmede bana yardımcı olmaz. \\
\hline UAK & Haritaları ve atlasları (dijital versiyonları dâhil) kullanmaktan hoşlanmam.
\end{tabular}

Görsel Okuryazarlık Yeterlikleri (GOY) Ölçeği; Kiper, Aslan, Kıyıcı ve Akgün (2012) tarafından geliştirilmiştir. 5'li Likert tipi şeklinde hazırlanan ölçekte yer alan maddeler “Kesinlikle Yapamam=1”, “Yapamam=2”, “Az Çok Yaparım=3”, “Yaparım=4” ve “Kolaylıkla Yaparım=5" şeklinde derecelendirilmiştir. Ölçek 29 madde ve 6 alt boyuttan oluşmaktadır. Ölçeğin alt boyutları 7 maddeden oluşan “Ofis Yazılımları Kullanarak Görselliğe Önem Verebilme (OYKGÖV)", 4 maddeden oluşan "Basılı Görsel Materyalleri Tanımlayabilme (BGMT)", 5 maddeden oluşan “Görsel Yorumlayabilme (GY)”, 5 maddeden oluşan “Günlük Hayatta Karşılaşılan Görsel Mesajları Ayırt Edebilme (GHKGMAE), 5 maddeden oluşan 
“Araçlar Kullanarak Görsel Üretebilme (AKGÜ)” ve 3 maddeden oluşan “Görsellerdeki Mesajları Algılayabilme (GMA)" olarak belirlenmiştir. Ölçeğin iç tutarlılık katsayısı .94 olarak rapor edilmiştir. Bu araştırma kapsamında ölçeğin iç tutarlılık katsayısı .91 olarak hesaplanmıştır. Pallant'a (2005) göre .70 ve üzerinde güvenirlik katsayısı sahip olan ölçeklerin güvenilir olduğu kabul edilmektedir. Tablo 2'de GOY ölçeğinin her boyutuna ilişkin örnek madde verilmiştir.

Tablo 2. GOY ölçeğinin her boyutuna ilişkin madde

\begin{tabular}{cl}
\hline Boyutlar & \multicolumn{1}{c}{ Örnek Madde } \\
\hline OYKGÖV & Yazılarımda grafik kullanırım. \\
\hline BGMT & Görsellerdeki karmaşı şekilleri tanımlarım. \\
\hline GY & Kavramları görsel şekillerle ifade ederim. \\
\hline GHKGMAE & Trafik işaretlerinin anlamlarını bilirim. \\
\hline AKGÜ & Fotoğraf, belge vs. taramak için tarayıcı kullanırım. \\
\hline GMA & Resim ya da fotoğrafların ne ifade ettiğini anlarım. \\
\hline
\end{tabular}

\section{Verilerin Analizi}

Bu araştırmada, SPSS 20.0 ve LISREL 8.54 paket programlarından yararlanılarak betimsel istatistikler, Pearson Momentler Çarpımı Korelasyonu ve yapısal eşitlik modeli kullanılmıştır.

Yapısal Eşitlik Modellemesi (YEM) gözlenen değişkenlerden hareketle gizil yapıları ölçmeyi amaçlayan çok değişkenli istatistiksel bir yöntemdir. Diğer temel istatistiksel yöntemlerden farklı olarak YEM'de doğrudan ölçülemeyen kavramlar modele yerleştirildiği ve tüm gözlenen değişkenlerdeki ölçüm hataları modele dahil edildiği için bu yönteme olan ilgi son yıllarda artmaktadır. YEM, "gözlenen değişkenleri gizil değişkenlere doğrulayıcı faktör analizi ile bağlayarak uygulanan ölçme modeli" ve "birbirine eşzamanlı eşitlik sistemleri ile bağlayarak uygulanan yapısal model" olmak üzere iki aşamadan oluşmaktadır (Yılmaz \& Varol, 2015). Bu araştırmada YEM'in analizine geçilmeden önce doğrulayıcı faktör analizi kullanılarak ölçme modelleri ayrı ayrı test edilmiştir (Çokluk, Şekercioğlu ve Büyüköztürk, 2012).

Araştırmada YEM'e başlamadan önce, örneklemden elde edilen veri seti için bazı sayıltı ve gereklilikler test edilmiştir. Bu amaçla öncelikle veri setinde gözlenen kayıp değerler için serilerin ortalamasını yansıtan değerler atanmıştır. Veri setinde yer alan değişkenlere ilişkin uç değerler Mahalanobis uzaklıkları kullanılarak incelenmiş ve uç değere sahip olduğu belirlenen dört gözlem veri setinden çıkarılmıştır. Çok değişkenli 
normallik incelemelerinden önce veri setinin tek değişkenli normalliği incelenmiş ve bu amaçla basıklık ve çarpıklık değerleri (-1 ve +1 aralığı) dikkate alınmıştır. Tek değişkenli normalliği bozduğu gerekçesiyle uç değer olan bir gözlem veri setinden çıkarıldıktan sonra tek değişkenli normallik varsayımı sağlanmıştır. Öte yandan değişkenler arasındaki saçılma diyagramları incelenerek de, çok değişkenli normallik ve doğrusallığın sağlandığı kabul edilmiştir.

YEM'de, kurgulanan modelin ölçekten elde edilen veriler tarafından doğrulanıp doğrulanmadığına belirlemek amacıyla uyum indekslerinden yararlanılmıştır. Çokluk vd.'ye (2012) göre bunlar ki-kare ve serbestlik derecesi oranı $\left(\chi^{2} / \mathrm{sd}\right)$, tahmin hatalarının ortalamasının karekökü (RMSEA), iyilik uyum indeksi (GFI), düzeltilmiş iyilik uyum indeksi (AGFI), standartlaştırılmış hata kareleri ortalamasının karekökü (SRMR), normlaştırılmamış uyum indeksi (NNFI) ve karşılaştırmalı uyum indeksidir (CFI). Uyum indekslerine ilişkin dikkate alınması gereken değerlendirme ölçütleri hakkında araştırmacılar arasında fikir ayrılıkları bulunmaktadır (Weston \& Gore, 2006). Bununla birlikte genel olarak, $\chi^{2} /$ sd oranının 5'in altında olması orta düzey, 3'ün altında olması mükemmel uyuma karşılık gelmektedir (Çokluk vd., 2012). RMSEA'nın .08'den küçük olması kabul edilebilir, .05'ten küçük olması mükemmel uyuma; GFI ile AGFI indekslerinin .85 'in üzerinde olması kabul edilebilir, $.90^{\prime}$ ın üzerinde olması mükemmel uyuma; NNFI ile CFI indekslerinin .90'ın üzerinde olması kabul edilebilir, .95 'in üzerinde olması mükemmel uyuma karşılık gelmektedir (Marcholudis \& Schumacher, 2007; Akt: Seçer, 2015). SRMR'nin ise .10'dan küçük olması kabul edilebilir, .05’ten küçük olması mükemmel uyum ölçütü olarak alınmaktadır (Bayram, 2013; Hu \& Bentler, 1999; Kline, 2011).

\section{Bulgular}

Zihnin Uzamsal Alışkanlıkları Ölçeği'nde yer alan ÖFE, UT, G, UKK, UAK değişkenleri ile Görsel Okuryazarlık Yeterlikleri Ölçeği'nde bulunan OYKGÖV, BGMT, GY, GHKGMAE, AKGÜ, GMA değişkenlerine ilişkin betimleyici istatistiklere ve değişkenler arası korelasyonlara Tablo 3 'te yer verilmiştir. 
Tablo 3. Betimleyici istatistikler ve korelasyon katsayıları

\begin{tabular}{|c|c|c|c|c|c|c|c|c|c|c|c|}
\hline Gizil Değişkenler & 1. & 2. & 3. & 4. & 5. & 6. & 7. & 8. & 9. & 10. & 11. \\
\hline 1.ÖFE & 1 & & & & & & & & & & \\
\hline 2.UT & $.460^{* *}$ & 1 & & & & & & & & & \\
\hline $3 . G$ & $.437^{* *}$ & $.434^{* *}$ & 1 & & & & & & & & \\
\hline 4.UKK & $.378^{* *}$ & $.471^{* *}$ & $.447^{* *}$ & 1 & & & & & & & \\
\hline 5.UAK & $.336^{* *}$ & $.399^{* *}$ & $.350^{* *}$ & $.467^{* *}$ & 1 & & & & & & \\
\hline 6.OYKGÖV & $.255^{* *}$ & $.249^{* *}$ & $.460^{* *}$ & $.290^{* *}$ & $.329^{* *}$ & 1 & & & & & \\
\hline 7.BGMT & $.441^{* *}$ & $.382^{* *}$ & $.387^{* *}$ & $.256^{* *}$ & $.479^{* *}$ & $.469^{* *}$ & 1 & & & & \\
\hline 8.GY & $.299^{* *}$ & $.301^{* *}$ & $.518^{* *}$ & $.294^{* *}$ & $.275^{* *}$ & $.569^{* *}$ & $.530^{* *}$ & 1 & & & \\
\hline 9.GHKGMAE & $.360^{* *}$ & $.285^{* *}$ & $.297^{* *}$ & $.277^{* *}$ & $.242^{* * *}$ & $.293^{* *}$ & $.338^{* *}$ & $.390^{* *}$ & 1 & & \\
\hline 10.AKGÜ & $.332^{* *}$ & $.229^{* *}$ & $.263^{* *}$ & .094 & $.204^{* *}$ & $.338^{* *}$ & $.392^{* *}$ & $.303^{* *}$ & $.336^{* *}$ & 1 & \\
\hline 11.GMA & $.364^{* *}$ & $.412^{* *}$ & $.494^{* *}$ & $.298^{* *}$ & $.291^{* *}$ & $.406^{* *}$ & $.499^{* *}$ & $.502^{* *}$ & $.393^{* *}$ & $.499^{* *}$ & 1 \\
\hline Ortalama & 3.64 & 3.26 & 3.70 & 3.45 & 3.50 & 3.84 & 3.43 & 3.94 & 4.13 & 3.19 & 3.57 \\
\hline Standart Sapma & .54 & .55 & .60 & .62 & .79 & .67 & .71 & .65 & .69 & .84 & .75 \\
\hline Çarpıklık & -.104 & .277 & -.373 & .052 & -.086 & -.057 & .067 & -.622 & -.666 & .102 & 181 \\
\hline Basıklık & .762 & .719 & .323 & -.293 & -.534 & -.260 & -.236 & .682 & .264 & -.314 & -.547 \\
\hline
\end{tabular}

${ }^{* *} \mathrm{p}<.01,{ }^{*} \mathrm{p}<.05$

Tablo 3 incelendiğinde, ZUA ölçeğinde yer alan "uzamsal kavram kullanımı (UKK)" değişkeni ile GOY ölçeğinde yer alan “araçlar kullanarak görsel üretebilme (AKGÜ)” değişkeni arasındaki korelasyon katsayısı dışındaki korelasyon katsayılarının istatistiksel olarak anlamlı olduğu saptanmıştır. Buna göre UKK ile AKGÜ alt boyutlar arasındaki ilişki dışındaki diğer tüm ilişkilerin arasında pozitif yönde, düşük ya da orta düzeyde anlamlı ilişkilerin olduğu söylenebilir.

Öğretmen adaylarının zihnin uzamsal alışkanlıklarının görsel okuryazarlık yeterliliklerinin anlamlı bir yordayıcısı olup olmadığı YEM ile incelenmiştir. Bu amaçla ilk olarak ZUA ile GOY’a ait ölçme modelleri doğrulayıcı faktör analizi kullanılarak ayrı ayrı test edilmiştir. ZUA'ya ait ölçme modelinde gizil değişkenlerin gözlenen değişkenleri açılama durumlarına ilişkin t değerleri 8.84 ile 10.46; GOY'a ait ölçme modelinde ise 7.48 ile 12.46 arasında değiştiği ve anlamlı olduğu tespit edilmiştir. Bununla birlikte ölçme modellerine ilişkin uyum indeksleri Tablo $4^{\prime}$ te verilmiştir.

Tablo 4. Ölçme modellerine ilişkin uyum indeksleri

\begin{tabular}{cccccccc}
\hline & $\chi^{2} /$ Sd & RMSEA & GFI & AGFI & SRMR & NNFI & CFI \\
\hline \multirow{2}{*}{ ZUA } & 1.11 & .022 & .99 & .97 & .023 & 1.00 & 1.00 \\
\cline { 2 - 8 } & Mükemmel & Mükemmel & Mükemmel & Mükemmel & Mükemmel & Mükemmel & Mükemmel \\
& uyum & uyum & uyum & uyum & uyum & uyum & uyum \\
\hline \multirow{2}{*}{ GOY } & 1.54 & .048 & .98 & .95 & .030 & .99 & .99 \\
\cline { 2 - 9 } & Mükemmel & Mükemmel & Mükemmel & Mükemmel & Mükemmel & Mükemmel & Mükemmel \\
& uyum & uyum & uyum & uyum & uyum & uyum & uyum \\
\hline
\end{tabular}


Tablo 4'teki elde edilen uyum indekslerine ilişkin sonuçlar, ölçme modellerinin doğrulandığı göstermektedir. Ölçme modellerine ait yol katsayıları ZUA ölçeğinde yer alan ÖFE, UT, G, UKK, UAK değişkenleri için .59 ile .68 arasında; GOY ölçeğinde yer alan OYKGÖV, BGMT, GY, GHKGMAE, AKGÜ, GMA değişkenleri için .49 ile .78 arasında değişmektedir. Ölçme modellerinin test edilmesi ve doğrulanmasının ardından zihnin uzamsal alışkanlıklarının görsel okuryazarlık yeterliliklerinin anlamlı bir yordayıcısı olup olmadığını tespit etmek için yol analizi yapılmıştır. Yol analizi neticesinde kurgulanan modele ilişkin tüm $\mathrm{t}$ değerlerinin 6.42 ile 11.13 arasında değiştiği ve anlamlı olduğu tespit edilmiştir. Modele ilişkin uyum indeksleri Tablo 5'te verilmiştir.

Tablo 5. Yol Analizine ilişkin uyum indeksleri

\begin{tabular}{cccccccc}
\hline $\begin{array}{c}\text { İncelenen } \\
\text { Uyum I. }\end{array}$ & $\chi^{2} / \mathrm{Sd}$ & RMSEA & GFI & AGFI & SRMR & NNFI & CFI \\
\hline $\begin{array}{c}\text { Elde Edilen } \\
\text { Uyum İ. }\end{array}$ & 2.49 & .079 & .93 & .88 & .054 & .95 & .96 \\
\hline Sonuç & $\begin{array}{c}\text { Mükemmel } \\
\text { uyum }\end{array}$ & $\begin{array}{c}\text { Kabul } \\
\text { edilebilir } \\
\text { uyum }\end{array}$ & $\begin{array}{c}\text { Mükemmel } \\
\text { uyum }\end{array}$ & $\begin{array}{c}\text { Kabul } \\
\text { edilebilir } \\
\text { uyum }\end{array}$ & $\begin{array}{c}\text { Kabul } \\
\text { edilebilir } \\
\text { uyum }\end{array}$ & $\begin{array}{c}\text { Mükemmel } \\
\text { uyum }\end{array}$ & $\begin{array}{c}\text { Mükemmel } \\
\text { uyum }\end{array}$ \\
\hline
\end{tabular}

Tablo 5'teki elde edilen uyum indekslerine ilişkin sonuçlar, zihnin uzamsal alışkanlıklarının görsel okuryazarlık yeterlilikleri üzerindeki yordayıcı etkisini tespit etmek için kurgulanan modelin doğrulandığını ortaya koymaktadır. Doğrulanan modele ilişkin yol şeması Şekil 1'de gösterilmiştir.

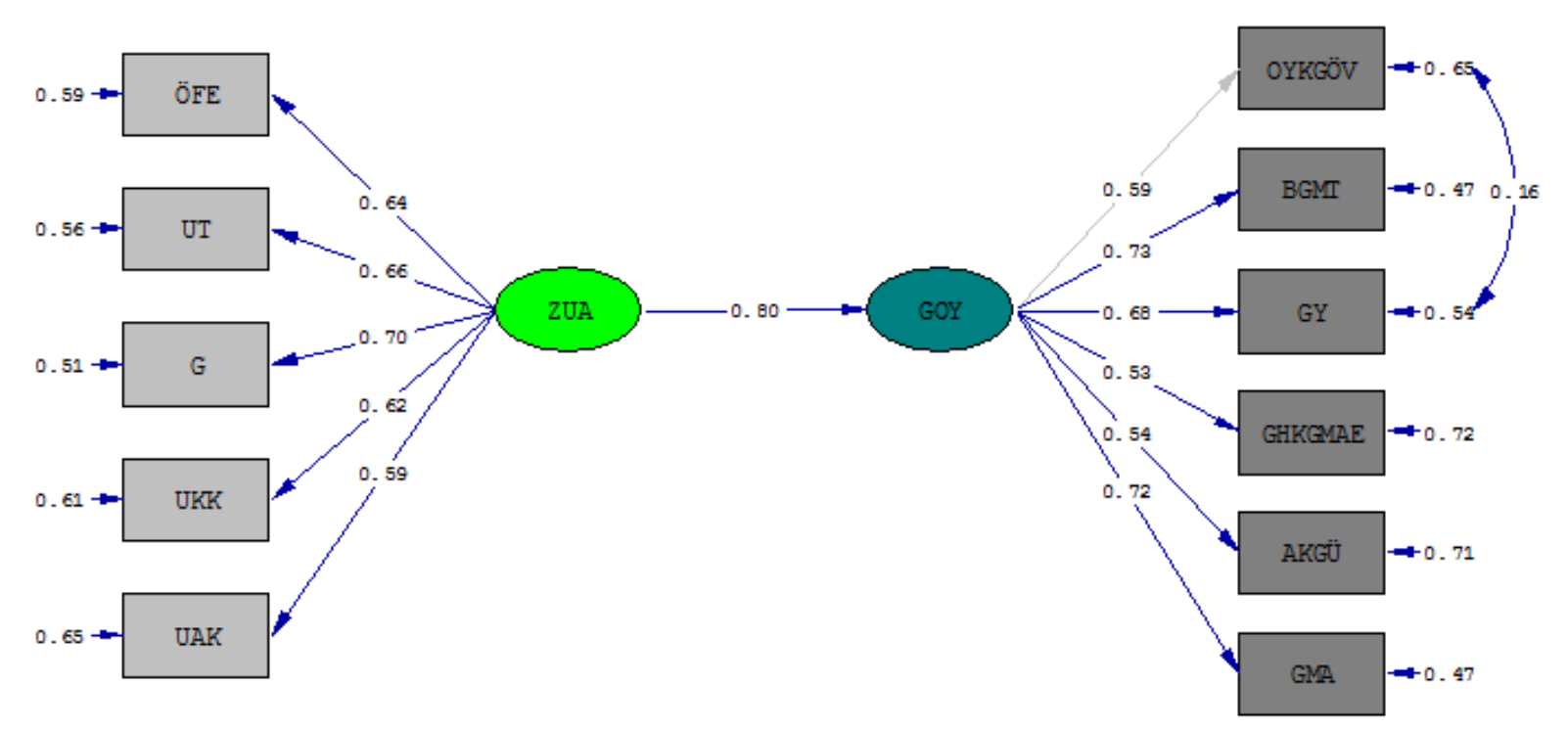

Chi-Square $=104.04, \mathrm{df}=42, \mathrm{P}-$ value $=0.00000, \mathrm{RMSEA}=0.079$

Şekil 1. Doğrulanan modele ilişkin yol şeması 
YEM'de belirleme katsayısı, yordayıcı değişkenlerin, yordanan değişkendeki varyansın ne kadarını açıkladığını göstermekte ve değerler 0 ile 1 aralığında değişmektedir (Seçer, 2014). Zihnin uzamsal alışkanlıkları değişkeninin görsel okuryazarlık yeterlilikleri değişkenindeki varyansları açıklama katsayıları Tablo 6'da verilmiştir.

Tablo 6. Modele ilişkin belirleme katsayıları

\begin{tabular}{cc}
\hline Uyum parametresi & Katsayı \\
\hline 1.ÖFE & .41 \\
$2 . \mathrm{UT}$ & .44 \\
$3 . \mathrm{G}$ & .49 \\
4.UKK & .39 \\
5.UAK & .35 \\
6.OYKGÖV & .35 \\
7.BGMT & .53 \\
8.GY & .46 \\
9.GHKGMAE & .28 \\
10.AKGÜ & .29 \\
11. GMA & .53 \\
\hline
\end{tabular}

Tablo 6 incelendiğinde, ZUA'ya ait ölçme modelinde zihnin uzamsal alışkanlıkları gizil değişkeni örüntüyü fark etmedeki varyansın \% 41'ini, uzamsal tasvirdeki varyansın \% 44'ünü, görselleştirmedeki varyansın \% 49'unu, uzamsal kavram kullanımındaki varyansın \% 39'unu ve uzamsal araç kullanımındaki varyansın \% 35'ini açıklamaktadır. GOY'a ait ölçme modelinde ise görsel okuryazarlık yeterlilikleri gizil değişkeninin ofis yazılımları kullanarak görselliğe önem verebilmedeki varyansın \% 35'ini, basılı görsel materyalleri tanımlayabilmedeki varyansın \% 53'ünü, görsel yorumlayabilmedeki varyansın \% 46'sını günlük hayatta karşılaşılan görsel mesajları ayırt edebilmedeki varyansın \% 28'ini, araçlar kullanarak görsel üretebilmedeki varyansın \% 29'unu ve görsellerdeki mesajları algılayabilmedeki varyansın \% 53'ünü açıklamaktadır. Bununla birlikte zihnin uzamsal alışkanlıkları ve görsel okuryazarlık yeterlilikleri arasında pozitif yönde anlamlı bir ilişki olduğu $[\beta=.80, t=7.74$ ve $p<.001]$ ve iki gizil değişken arasında paylaşılan ortak varyansın $\%$ 63'ünün model tarafından açıklandığı ortaya çıkmıştır [ $\left.R^{2}=.63\right]$.

Zihnin uzamsal alışkanlıkları ve görsel okuryazarlık yeterliliklerinin ÖFE, UT, G, UKK, UAK, OYKGÖV, BGMT, GY, GHKGMAE, AKGÜ, GMA üzerindeki toplam ve dolaylı etkileri Tablo 7'de gösterilmiştir. 
Tablo 7. ZUA ve GOY'nin değişkenler üzerindeki toplam ve dolaylı etkileri

\begin{tabular}{cccc}
\hline \multicolumn{3}{c}{ Toplam Etki } & Dolayl Etki \\
\hline & ZUA & GOY & ZUA \\
\hline 1.ÖFE & .64 & & \\
2.UT & .66 & & \\
3.G & .70 & & \\
4.UKK & .62 & & \\
5.UAK & .59 & & .31 \\
6.OYKGÖV & & .59 & .41 \\
7.BGMT & & .74 & .35 \\
8.GY & & .69 & .29 \\
9.GHKGMAEG & & .52 & .36 \\
10.AKGÜ & & .50 & .43 \\
11.GMA & & .70 & \\
\hline
\end{tabular}

Tablo 7'de zihnin uzamsal alışkanlıkları gizil değişkeninin ÖFE, UT, G, UKK, UAK'yı doğrudan etkilediği; OYKGÖV, BGMT, GY, GHKGMAE, AKGÜ, GMA değişkenlerini ise görsel okuryazarlık yeterlilikleri gizil değişkeni üzerinden dolaylı olarak etkilediği görülmektedir. Ayrıca, görsel okuryazarlık yeterlilikleri gizil değişkeni OYKGÖV, BGMT, GY, GHKGMAE, AKGÜ, GMA değişkenlerini doğrudan etkilemektedir.

\section{Tartışma, Sonuç ve Öneriler}

$\mathrm{Bu}$ araştırmada zihnin uzamsal alışkanlıklarının öğretmen adaylarının görsel okuryazarlık yeterlilikleri üzerindeki yordayıcı etkisi yapısal eşitlik modeli ile incelenmiştir. $\mathrm{Bu}$ amaçla araştırmada iki hipotez sınanmıştır. Buna göre, birinci hipotez zihnin uzamsal alı̧̧kanlıklarının görsel okuryazarlık yeterlilikleri ile ilişkili olacă̆ $ı$ ve ikinci hipotez zihnin uzamsal alışkanlıklarının öğretmen adaylarının görsel okuryazarlık yeterliliklerini anlamlı olarak yordayacă̆ şeklindedir. Araştırmada elde edilen bulguya göre, zihnin uzamsal alışkanlıkları ile görsel okuryazarlık yeterlilikleri arasında pozitif yönde anlamlı bir ilişki olduğu ortaya çıkmış ve ilk hipotez doğrulanmıştır. Bu bulgu, öğretmen adaylarının uzamsal zihin alışkanlıklarını geliştirmelerinin, onların görsel okuryazarlık yeterliliklerini olumlu yönde etkileyeceği anlamına gelmektedir. Nitekim zihin alışkanlıkları ile ilgili araştırmalar öğrencilerin zihin alışkanlıklarını geliştirmelerinin oldukça önemli olduğunu ve öğrencilerin geliştirdikleri alışkanlıklarını derslerine transfer edebileceklerini ortaya koymuştur (Mark, Cuoco, Goldenberg \& Sword, 2010). Bir kişinin olguları görselleştirmesine, düzenlemesine, yeniden yapılandırmasına ve genelleştirmesine olanak tanıyan uzamsal yetenek (Turgut, 2015) mimari, haritacılık, jeoloji, astronomi, mühendislik, matematik, biyokimya, biyoloji, kimya, 
fizik gibi alanlar ile pozitif ilişkilidir (Hartman \& Bertoline, 2005). Benzer şekilde görsel mesajları oluşturma ve anlamlandırma gücü olarak tanımlanan görsel okuryazarlık da grafik tasarım, görsel sanatlar, mühendislik, mimarlık, öğretim teknolojisi, endüstri ürünleri tasarımı vb. alanların ilgilendiği disiplinler arası bir kavramdır (Alpan, 2008). Bu durumda uzamsal yeteneğin kullanımını gerektiren uzamsal zihin alışkanlıkları ile görsel okuryazarlık yeterliliklerinin ilişkili olması beklenen bir durumdur. Demir ve Aybek (2012) yapmış oldukları araştırmada ise görsel öğrenme stili ile görsel/uzamsal zekâ alanı arasında güçlü ilişki olduğunu tespit etmişlerdir. Araştırmadan elde edilen diğer bulguya göre, zihnin uzamsal alışkanlıklarının öğretmen adaylarının görsel okuryazarlık yeterliliklerini anlamlı olarak yordadığı tespit edilerek ikinci hipotezinde doğrulandığı ortaya çıkmıştır. Buna göre zihnin uzamsal alışkanlıklarının görsel okuryazarlık yeterliliklerindeki varyansın \% 63'ünü açıkladığı ortaya çıkmıştır. Bu bulgu zihnin uzamsal alışkanlıklarının öğretmen adaylarının görsel okuryazarlık yeterlilikleri üzerinde önemli bir etkisinin olduğu anlamına gelmektedir. Görsel okuryazarlık, günlük yaşamda karşılaşılan sorunları görsel veya uzamsal çerçeveler içinde algılama, anlama, yorumlama, değerlendirme ve kullanma yeterliliğidir (Bekdemir \& Duran, 2012). Yüzeysel ve uzamsal kavramları, cisimleri, şekilleri ve bunların temsilcilerini tanıyabilme ve analiz edebilme için gerekli olan bilgi ve beceriler de görsel okuryazarlıkla ilişkilidir (NCF, 2005; Robertson, 2007; Akt: Yağcı, Bozyokuş \& Ezentaş, 2016). Saban'a (2005) göre de görsel-uzamsal zekâya sahip olan bireyler görsel mesajları, diyagramları, haritaları, tabloları, yazılı materyallere kıyasla daha kolay okuyup anlamaktadırlar (Akt: Lüle-Mert, 2017). Dolayısıyla bu zekaya sahip bireylerin görsel okuryazarlık yeterliliklerinin de yüksek olması beklenir. Nitekim Kim ve Bednardz (2013) da insanların zihnin uzamsal alışkanlıklarına sahip olması görsel-uzamsal okuryazarlık yeterlilikleri için önemli olduğunu ifade etmişlerdir.

Zihnin uzamsal alışkanlıkları örtük değişkeni en fazla görselleştirme boyutundaki varyansı açıklamaktadır. Bunun nedeni bu değişkenin görsel okuryazarlık yeterlilikleri ve alt boyutları ile daha yakından ilişkisi olması ile açılanabilir. Çünkü görselleştirme, grafik temsillerin yardımıyla anlama çabasıdır (Blaser, Sester \& Egenhofer, 2000). Zihnin uzamsal alışkanlıklarından olan görselleştirme alışkanlığına sahip olan bireylere bilgi veya veriler sözlü olarak aktarılırsa, bu bireyler bilgiyi grafikler veya diyagramlar gibi görsel temsillere dönüştürerek anlamaya çalışırlar. Dolayısıyla bu bireyler grafik temsillerin yararını ve gücünü bilir ve bu nedenle, diğer insanlara bilgi vermek ve kendi anlayışını geliştirmek için 
sıklıkla görselleştirme stratejileri kullanırlar (Rieber, 1995). Öte yandan görsel okuryazarlık yeterlilikleri gizil değişkeni en fazla basılı görsel materyalleri tanımlayabilme boyutundaki varyansı açıklamaktadır. Araştırmanın bir diğer bulgusu zihnin uzamsal alışkanlıkları gizil değişkeninin örüntüyü fark etme, uzamsal tasvir, görselleştirme, uzamsal kavram kullanımı ve uzamsal araç kullanımını doğrudan; ofis yazılımları kullanarak görselliğe önem verebilme, araçlar kullanarak görsel üretebilme, günlük hayatta karşılaşılan görsel mesajları ayırt edebilme, görsel yorumlayabilme, görsellerdeki mesajları algılayabilme, basılı görsel materyalleri tanımlayabilme değişkenlerini ise görsel okuryazarlık yeterlilikleri gizil değişkeni üzerinden dolaylı olarak etkilediği şeklindedir.

Sonuç olarak, araştırmada öğretmen adaylarının zihnin uzamsal alışkanlıklarının, onların görsel okuryazarlık yeterliliklerinin anlamlı bir yordayıcısı olduğu ortaya çıkmıştır. Buna göre öğretmen adaylarının görsel okuryazarlıklarına etki eden değişkenlerden birinin kullandıkları uzamsal zihin alışkanlıkları olduğu söylenebilir. Buna göre, öğretmen adaylarının öğrenme ve öğretme süreçlerine katkı sağlayan görsel okuryazar yeterliliklerinin geliştirilmesinde bu araştırmanın bulgularından yararlanılabilir. İleride yapılacak araştırmalarda öğretmen adaylarının görsel okuryazarlık yeterliliklerinin diğer değişkenlerle olan ilişkisi incelenebilir. Farklı üniversitelerde öğrenim gören farklı branşlardaki öğretmen adayları ile benzer araştırmalar yapılabilir.

\section{Bilgilendirme}

Bu çalışmada kullanılan verilerin 2020 yılı öncesine ait olduğu araştırmacı tarafindan onaylanmıştır.

Yazar Katkı Beyanı

Neşe DOKUMACI SüTÇÜ: Kavramsallaştırma, metodoloji, danışmanlık ve denetim (öğretim materyali, ölçme aracı, veri analizi), inceleme-yazma ve düzenleme.

\section{Kaynaklar}

Akkoyunlu, B. \& Yılmaz, M. (2005). Öğretmen adaylarının bilgi okuryazarlık düzeyleri ile internet kullanım sıklıkları ve internet kullanım amaçları. Eurasian Journal of Educational Research, 19, 1-14.

Alpan, G. (2008). Görsel okuryazarlık ve öğretim teknolojisi. Yüzüncü Yıl Üniversitesi Ĕ̆gitim Fakültesi Dergisi, 5(2), 74-102. 
Astatin, H., Mayasari, T., Huriawati, F., \& Oi, R. (2020). Vocational high school students' habits of mind in physics material through discovery learning models. JIPF (Jurnal Ilmu Pendidikan Fisika), 5(2), 73-81.

Avgerinou, M. D. \& Pettersson, R. (2011). Toward a cohesive theory of visual literacy. Journal of Visual Literacy, 30(2), 1-19.

Bayram, N. (2013). Yapısal eşitlik modellemesine giriş, AMOS uygulamaları. Bursa: Ezgi Kitabevi. Bekdemir, M. \& Duran, M. (2012). İlköğretim öğrencileri için görsel matematik okuryazarlığ1 öz yeterlik algı ölçeği (GMOYÖYAÖ)'nin geliştirilmesi. Ondokuz Mayıs Üniversitesi Eğitim Fakültesi Dergisi, 31(1), 89-115.

Benzer, E. (2020). Bilimsel okuryazarlık ve medya okuryazarlığı arasındaki ilişki: Fen bilgisi öğretmen adayları örneği. Araştırma ve Deneyim Dergisi, 5(1), 10-23.

Blaser, A. D., Sester, M., \& Egenhofer. M. J. (2000). Visualization in an early stage of the problem-solving process in GIS. Computers $\mathcal{E}$ Geosciences, (26), 57-66.

Costa, A. L. (2008). Describing the habits of mind. In A. L. Costa and B. Kallick (Ed.), Learning and leading with habits of mind: 16 essential characteristics for success (pp.15-41). Alexandria, VA: Association for Supervision and Curriculum Development.

Cuoco, A., Goldenberg, E. P., \& Mark, J. (1996). Habits of mind: An organizing principle for mathematics curricula. The Journal of Mathematical Behavior, 15(4), 375-402.

Çeker (2018). Aday ortaokul matematik öğretmenlerinin zihnin uzamsal alışkanlıklar düzeyleri (Yayımlanmamış yüksek lisans tezi). Eskişehir Osmangazi Üniversitesi, Eskişehir.

Çokluk, Ö., Şekercioğlu, G., \& Büyüköztürk, Ş. (2012). Sosyal bilimler için çok değişkenli istatistik SPSS ve LISREL uygulamaları (2.Baskı). Ankara: Pegem Akademi Yayıncılık.

Demir, R. \& Aybek, B. (2012). Dokuzuncu sınıf öğrencilerinin öğrenme stilleri ve çoklu zeka alanlarının incelenmesi. Uluslararası Ĕğitim Programları ve Öğretim Çalışmaları Dergisi, 2(4), 27-40.

Eraslan-Taşpınar, Ş. (2016). Sanat eğitiminin görsel okuryazarlık becerilerine etkisi. The Turkish Online Journal of Design, Art and Design (TOJDAC), 1(6), 335-342.

Fraenkel, J. R., Wallen, N. E., \& Hyun, H. H. (2012). How to design and evaluate research in education (8. Edition). McGraw-Hill.

Goldenberg, E. P., Mark, J., \& Cuoco, A. (2010). Contemporary curriculum issues: An algebraic-habits-of-mind perspective on elementary school. Teaching Children Mathematics, 16(9), 548-556.

Hartman, N. W. \& Bertoline, G. R. (2005). Spatial abilities and virtual technologies: Examining the computer graphics learning environment. In Information Visualisation Proceedings. Ninth International Conference (pp. 992-997). IEEE.

Hu, L. \& Bentler, P. M. (1999). Cutoff criteria for fit indexes in covariance structure analysis: Conventional criteria versus new alternatives. Structural Equation Modeling, 6(1), 1-55.

Karasar, N. (2011). Bilimsel araştırma yöntemi (22. Baskı). Ankara: Nobel Yayın Dağıtım.

Kaya, D. (2017). Altıncı sınıf öğrencilerinin cebir öğrenme alanındaki başarı düzeylerinin incelenmesi. International e-Journal of Educational Studies (IEJES), 1 (1), 47-59. 
Kaya, V. H. (2017). Duygusal zekanın 1şığında bilişim teknolojisi ve öğrenci duygularının fen bilimleri okuryazarlığı ile ilişkisinin belirlenmesi. Journal of Computer and Education Research, 5(10), 194-217.

Kaya, V. H. \& Elster, D. (2019). Dimensions affecting environmental literacy, and environmental perceptions influencing science literacy. International e-Journal of Educational Studies, 3(6), 70-77.

Kim, M. \& Bednarz, R. (2013). Effects of a GIS course on self-assessment of spatial habits of mind (SHOM). Journal of Geography, 112(4), 165-177.

Kim, M. (2011). Effects of a GIS course on three components of spatial literacy (Doctoral dissertation). Seoul National Universty, South Korea.

Kiper, A., Arslan, S., Kıyıc1, M., \& Akgün, Ö. E. (2012). Visual literacy scale: the study of validity and reliability. The Online Journal of New Horizons in Education, 2(2), 73-83.

Kiper, A., Kırksekiz, A., \& Çam, E. (2014, Mayıs). Üniversite öğrencileri görsel okuryazarlık yeterlilikleri. Instructional Technologies \& Teacher Education Symposium, At Afyonkarahisar, Turkey

Kline, R. B. (2011). Principles and practice of structural equation modeling. New York: The Guilford Press.

Köse, Y. N. \& Tanışlı, D. (2014). Sınıf öğretmeni adaylarının geometrideki zihinsel alışkanlıkları. Kuram ve Uygulamada Eğitim Bilimleri, 14(3), 1203-1230.

Kul, S. (2020). Dijital okuryazarlık ve diğer değişkenlerle internet bağımlılığ incelenmesi. Uluslararası Yönetim Bilişim Sistemleri ve Bilgisayar Bilimleri Dergisi, 4(1), 2841.

Leikin, R. (2007). Habits of mind associated with advanced mathematical thinking and solution spaces of mathematical tasks. Paper presented at the The Fifth Congress of the European Society for Research in Mathematics Education, Division 14: Advanced Mathematicsl Thinking, February 22-26, Larnaca, Cyprus.

Lüle-Mert, E. (2017). 6. ve 8 . sınıf öğrencilerinin görsel okuryazarlık yeterlilikleri. International Journal of Languages' Education and Teaching, 5(1), 255-266.

Marita, R. A. S. (2014). Profil habits of mind siswa sma kelas x1 pada pembelajaran biologi menggunakan metode praktikum dan diskusi. Mathematıcs and Sciences Forum.

Mark, J., Cuoco, A., Goldenberg, E. P. \& Sword, S. (2010). Developing mathematical habits of mind. Mathematics teaching in the Middle School, 15(9), 505-509.

Marzano, R. J. (1992). A different kind of classroom: Teaching with dimensions of learning. Association for Supervision and Curriculum Development, 1250 North Pitt Street, Alexandria, VA.

Milner-Bolotin, M. \& Nashon, S. M. (2012). The essence of student visual-spatial literacy and higher order thinking skills in undergraduate biology. Protoplasma, 249(1), 25-30.

Özgen, K. \& Kutluca, T. (2013). İlköğretim matematik öğretmen adaylarının matematik okuryazarlığına yönelik görüşlerinin incelenmesi. Dicle Üniversitesi Sosyal Bilimler Enstitüsü Dergisi, 5(10), 1-22. 
Pallant, J. (2005). SPSS survival manual. a step by step guide to data analysis using SPSS for windows. Australia: Australian Copyright.

Rieber, L. P. (1995). A historical review of visualization in human cognition. Educational Technology Research and Development, 43, 45-56.

Sadıç, A. \& Çam, A. (2015). 8. sınıf öğrencilerinin epistemolojik inançları ile pisa başarıları ve fen ve teknoloji okuryazarlığı. Journal of Computer and Education Research, 3(5), 18-49.

Seçer, İ. (2014). Analysis of the relations between obsessive compulsive symptoms and anxiety sensitivity in adolescents with structural equation modeling. Eğitim ve Bilim, 39(176), 369-382.

Seçer, İ. (2015). Psikolojik test geliştirme ve uyarlama süreci, SPSS ve LISREL uygulamaları. Ankara: Anı Yayıncilık.

Şahin, Ç. \& Kıran, I. (2009). Öğretmen adaylarının algılarına göre görsel okuryazarlık düzeylerinin değerlendirilmesi. Dumlupınar Üniversitesi Sosyal Bilimler Dergisi, 23, 7790.

Şahin, Ç., Kurudayığlu, M., \& Çelik, G. (2013). Türkçe öğretmeni adaylarının görsel okuryazarlıkları üzerine bir araştırma. Ana Dili Ĕ̆itimi Dergisi, 1(1), 129-143.

Turgut, M. (2015). Individual differences in the mental rotation skills of Turkish prospective teachers. IUMPST: The Journal, (5), 1-12.

Ünveren-Bilgiç, E.N., \& Argün, Z. (2018). Examining middle school mathematics teacher candidates' algebraic habits of mind in the context of problem solving. International eJournal of Educational Studies (IEJES), 2 (4), 64-80

Weston, R. \& Gore, P. A. (2006). A brief guide to structural equation modeling. The Counseling Psychologist, 34(5), 719-751

Yağcl, F., Bozyokuş, H., \& Ezentaş, R. (2016). Grafik tasarım programlarında geometrik okuryazarlık. Journal of Current Researches on Social Sciences, 6(2), 57-64.

Yılmaz, V. \& Varol, S. (2015). Hazır yazılımlar ile yapısal eşitlik modellemesi: Amos, Eqs, Lisrel. Dumlupınar Üniversitesi Sosyal Bilimler Dergisi, (44), 28-44.

Yüksel-Gemalmayan, R. (2014). Görsel sanatlar eğitiminde görsel okuryazarlık ve temel tasarım öğretimi. Sakarya Üniversitesi Ĕ̆itim Fakültesi Dergisi, 27, 95-120.

Zeren, G. \& Arslan, R. (2009). Bir eğitim süreci olarak görsel okuryazarlık. Türkiye Sosyal Araştırmaları Dergisi, 13(3), 43-52. 